
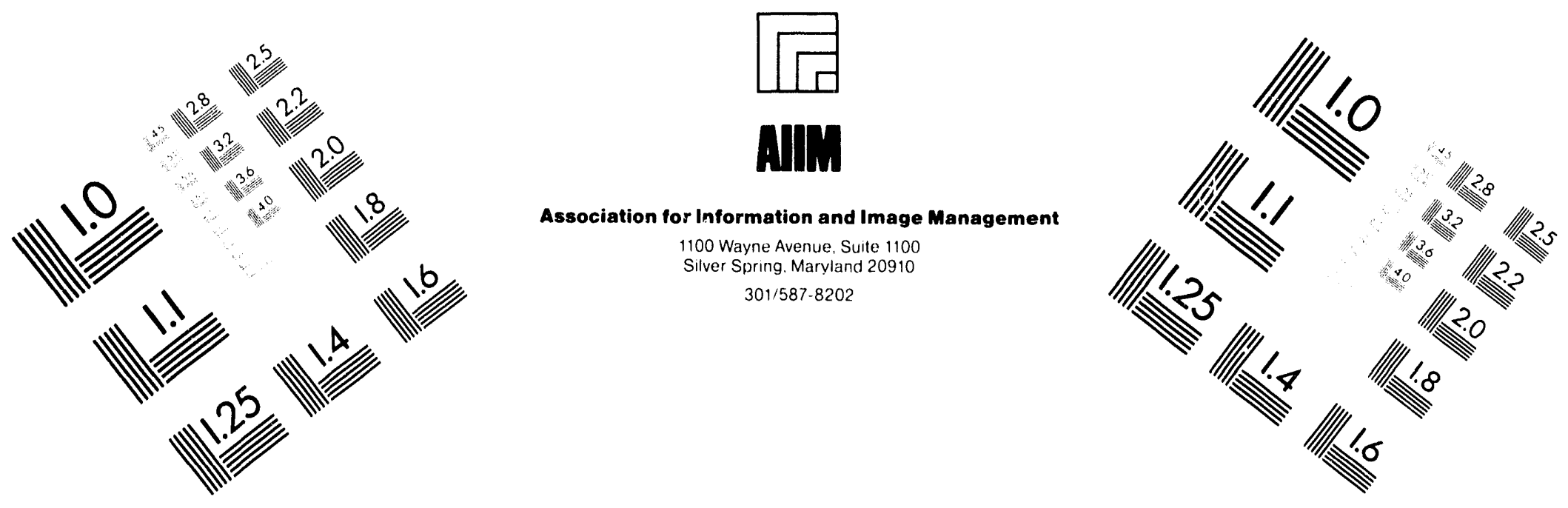

\title{
Centimeter
} Lш

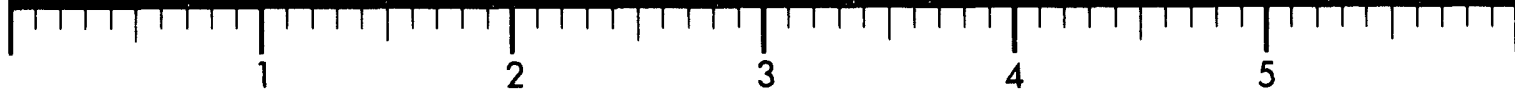
Inches
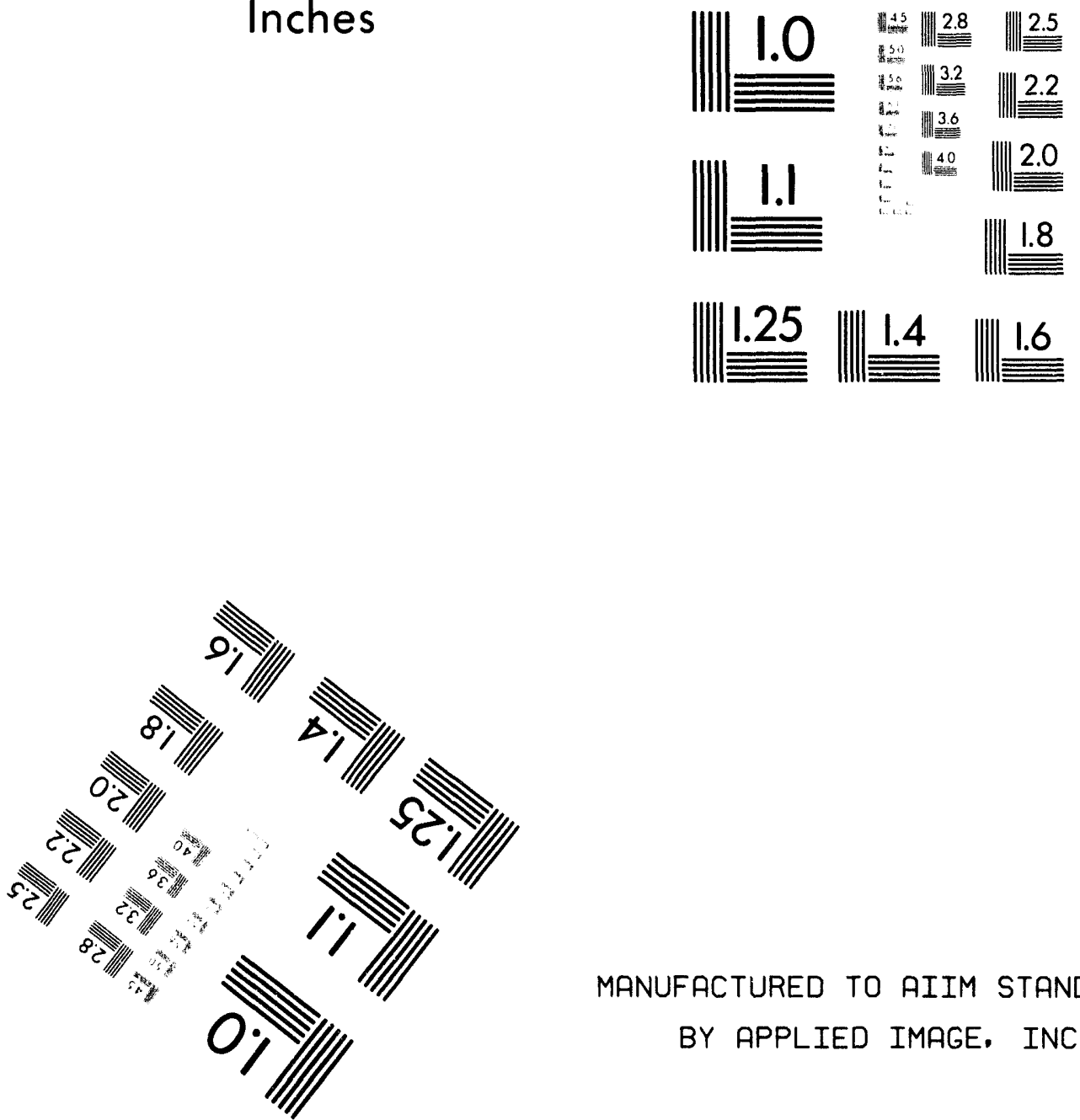

MANUFACTURED TO AIIM STANDARDS BY APPLIED IMAGE, INC.

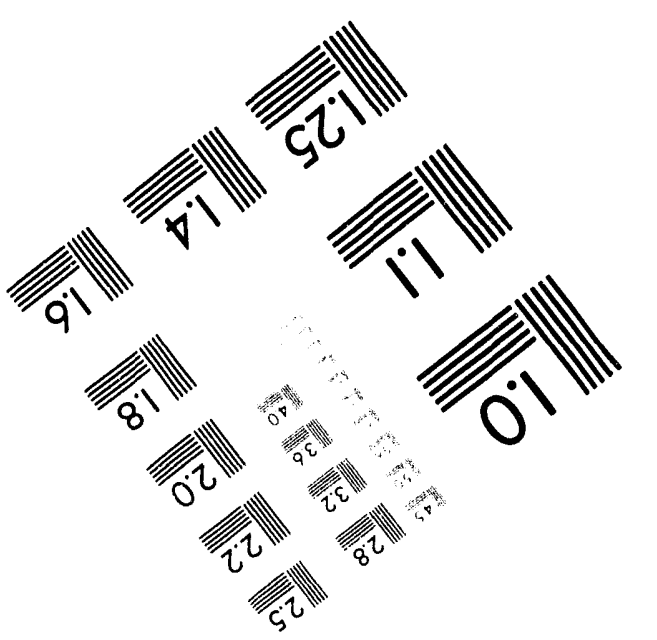



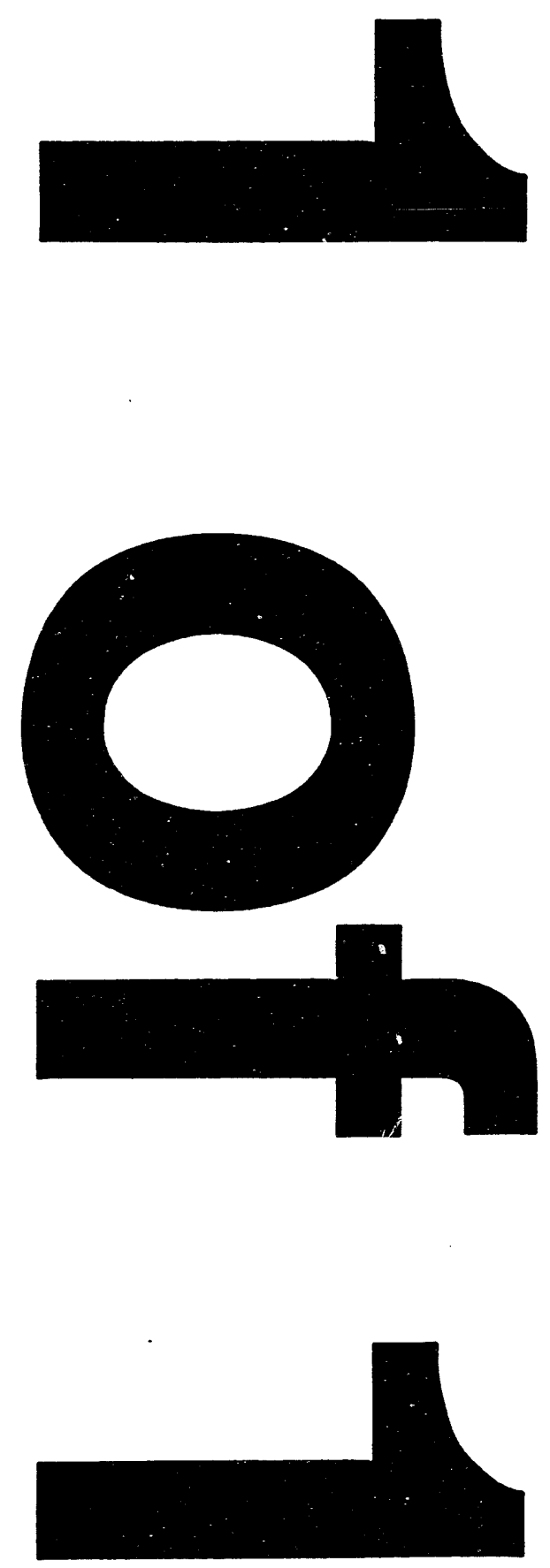
2. To: (Receiving Organization)

3. From: (Originating Organization) 200/300 Area Projects

Record File

5. Proj./Prog./Dept./Div.:

300-FF-5 Remedial

Investigation

8. Originator Remarks:

Release to Record File
6. Cog. Engr.:

L.C. Hulstrom
4. Related EDT NO.:

N/A

7. Purchase Order No.:

$N / A$

9. Equip./Component No.:

$N / A$

10. System/8ldg./Facility:

$N / A$

11. Receiver Remarks:

12. Major Assm. Dwg. No.:

$N / A$

13. Permit/Permit Application Mo.: $N / A$

14. Required Response Date:

None

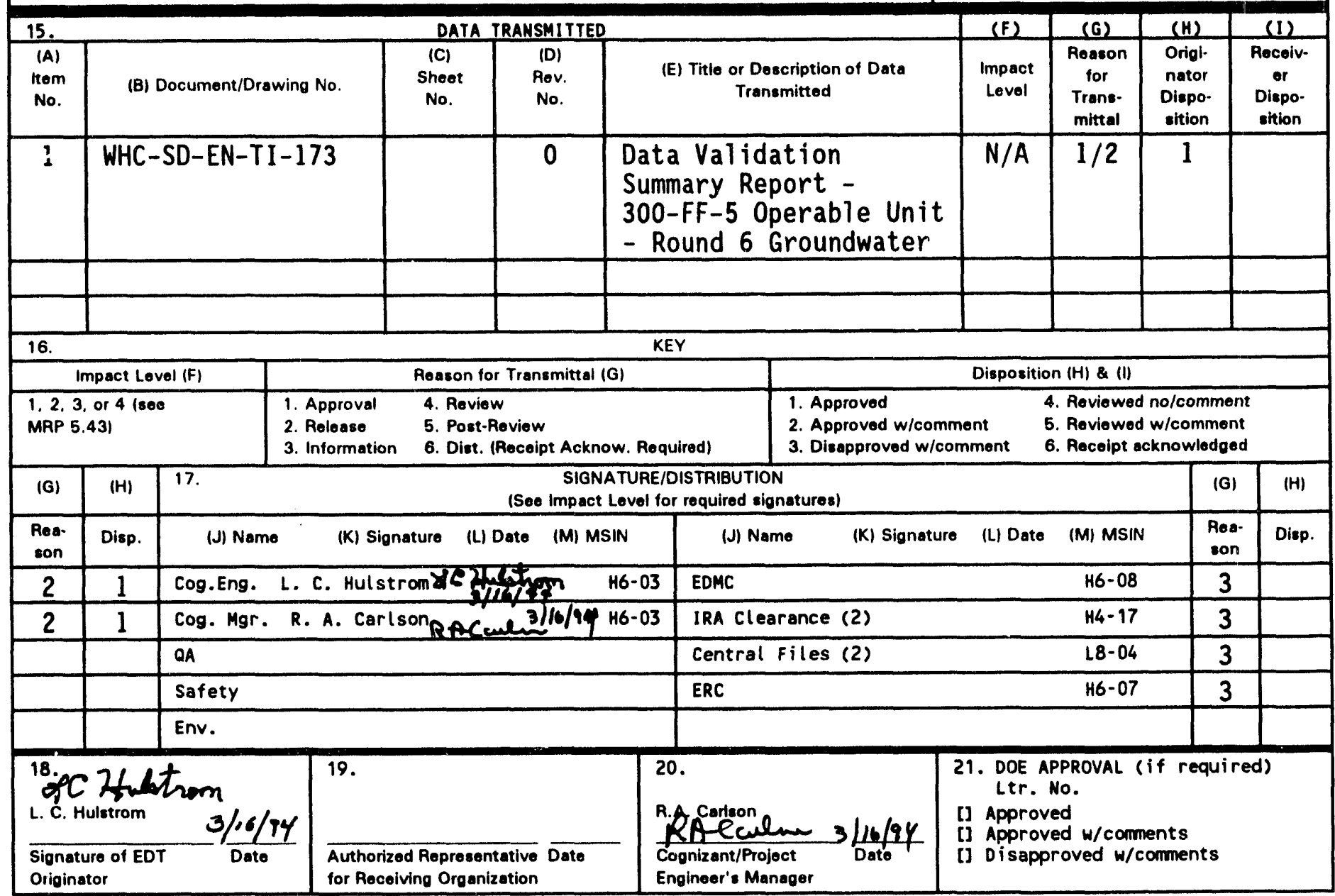

$B D-7400-172-2(07 / 91)$ GEF097 


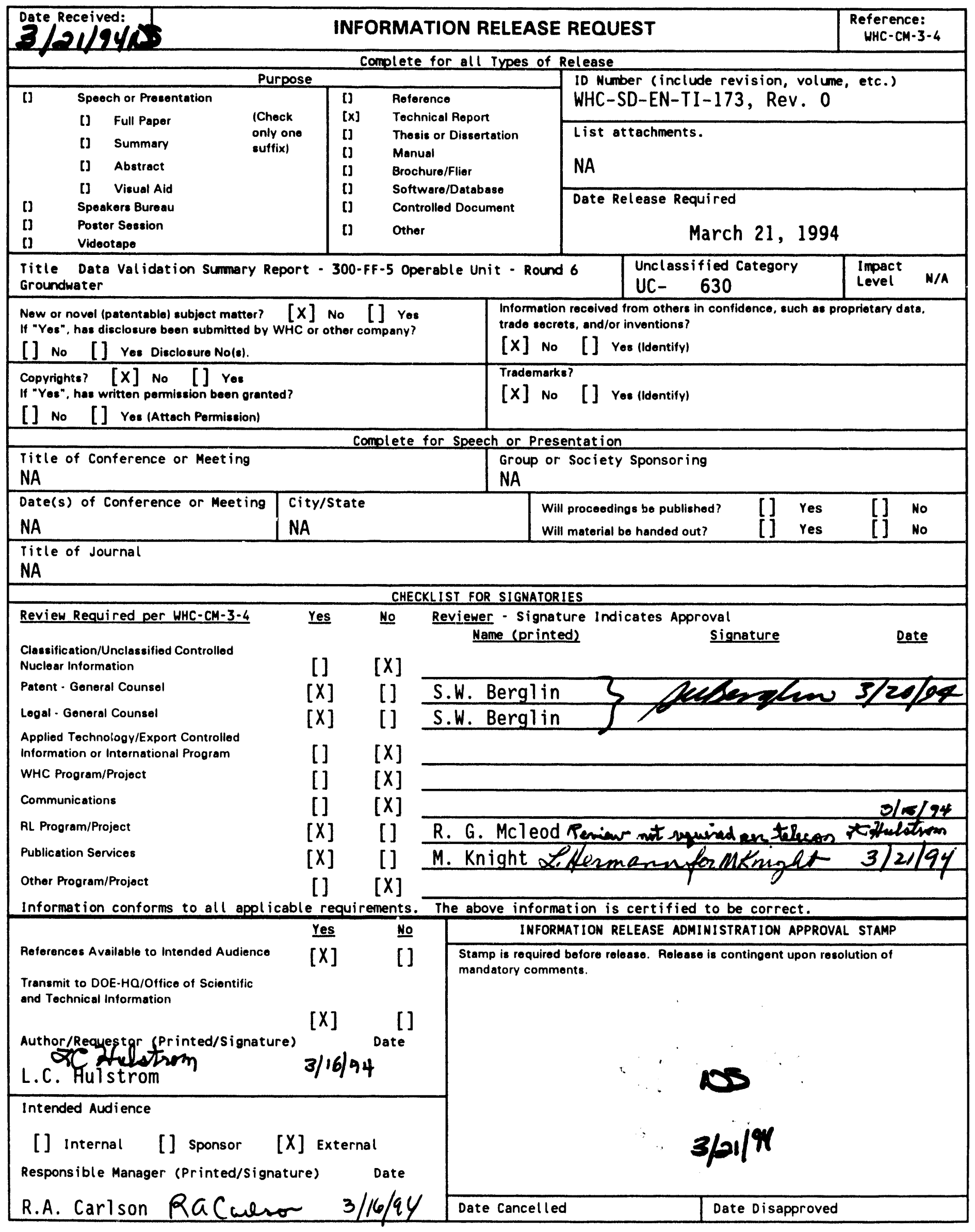




\begin{tabular}{|c|c|}
\hline \multicolumn{2}{|l|}{ SUPPORTING DOCUMENT } \\
\hline $\begin{array}{l}\text { 2. Title } \\
\text { Data Validation Summary Report:-300-FF-5 Operable } \\
\text { Unit, } 2 \text { Round } 6 \text { Groundwater }\end{array}$ & $\begin{array}{l}\text { 3. Number } \\
\text { WHC-SD-EN-TI-173 }\end{array}$ \\
\hline $\begin{array}{l}\text { 5. Key Words } \\
\text { TMA VOA, I sotopic and Total Uranium analyses - Case \#'s } \\
\text { A309082, A309049, A310001, A309074, M3-09-066-7245, N3-09-124-7264, } \\
\text { and N3-09-151-7268 } \\
\text { Weston VOA, I sotopic and Total Uranium analyses - Case \#'s 9309L093, } \\
9309 L 018 .\end{array}$ & $\begin{array}{l}\text { 6. Author } \\
\text { Name: L. C. Hulstrom } \\
\text { signature Afulatiom 3/15/94 } \\
\text { Organization/Charge code } 8 C 300 / \text { P25AE }\end{array}$ \\
\hline $\begin{array}{l}\text { 7. Abstract } \\
\text { Hulstrom, L. C., 1994, Data Validation Summary Repor } \\
\text { Round } 6 \text { Groundwater, WHC-SD-EN-TI-173, Rev. 0, prepa } \\
\text { (formerly Ebasco Environmental) and Hart Crowser, fo } \\
\text { Richland, Washington. }\end{array}$ & $\begin{array}{l}\text {-5 Operable U } \\
\text { ERCH Environm } \\
\text { ouse Hanford }\end{array}$ \\
\hline 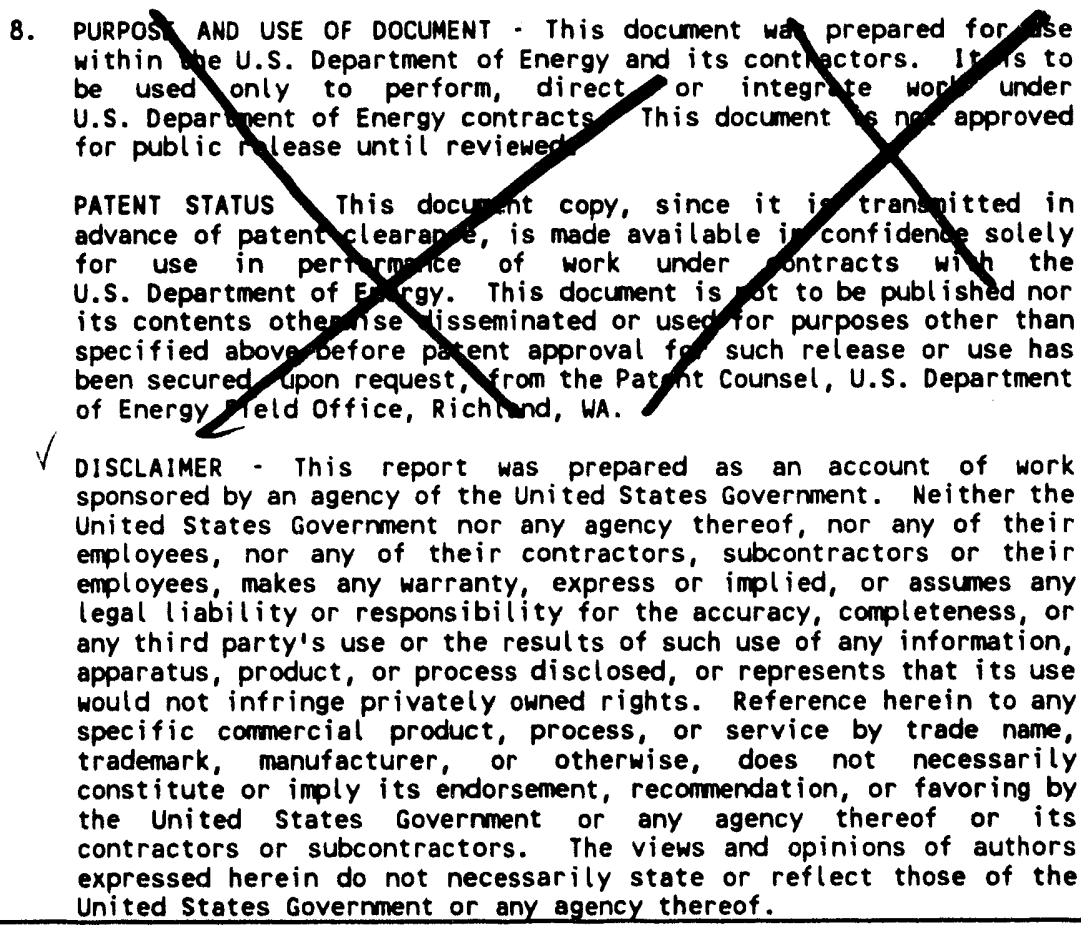 & $\begin{array}{l}\text { OFFICII, RELEASE } 11 \\
\text { EY WHC } \\
\text { DATE MAR } 231994 \\
\text { SLACEX }\end{array}$ \\
\hline 9. Impact Level $N / A$ & \\
\hline
\end{tabular}




\section{WHC-SD-EN-TI-173, Rev. 0}

\section{CONTENTS}

Page

ACRONYMS iv

1.0 INTRODUCTION $1-1$

1.1 CHEMICAL ANALYSES $1-1$

1.2 RADIOCHEMICAL ANALYSES $1-1$

1.3 WESTINGHOUSE HANFORD GUDANCE USED $1-1$

1.4 MAJOR DEFICIENCIES $1-2$

1.5 GENERAL QUALITY TRENDS $1-2$

2.0 VOLATILE ORGANIC DATA VALDATION AND LIMITATIONS $2-1$

$\begin{array}{ll}2.1 \text { SUMMARY } & 2-1\end{array}$

2.1.1 Six Sample Delivery Groups $2-1$

2.1.2 All Samples Validated 2-1

2.1.3 Westinghouse Hanford Validation Guidance Used $2-1$

2.1.4 Samples Analyzed According to CLP Protocols 2-1

$\begin{array}{lr}\text { 2.1.5 Minor Deficiencies Noted } & 2-2\end{array}$

2.2 ANALYTICAL METHOD $2-2$

2.2.1 Gas Chromatography/Mass Spectrometer (GC/MS) Tuning Criteria Met 2-2

$\begin{array}{lr}\text { 2.2.2 Acceptable Calibration } & 2-2 \\ 2.2 & \text { Banks }\end{array}$

2.2.3 Blanks 2-3

2.3 HOLDING TIMES $2-4$

$\begin{array}{lr}2.4 \text { ACCURACY } & 2-4\end{array}$

2.4.1 Surrogate Compound Recovery Acceptable 2-4

2.4.2 Matrix Spike Recoveries Acceptable $2-5$

$\begin{array}{ll}2.5 & \text { PRECISION ACCEPTABLE } \\ 2-5\end{array}$

2.5.1 Matrix Spike Duplicates Acceptable 2-5

2.5.2 Field Duplicates Acceptable $2-5$

$\begin{array}{lr}\text { 2.5.3 Split Samples Acceptable } & 2-5\end{array}$ 
CONTENTS (Continued)

Page

2.6 INTERNAL STANDARD PERFORMANCE ACCEPTABLE $2-6$

$\begin{array}{ll}2.7 \text { IDENTIFICATION OF COMPOUNDS } & 2-6\end{array}$

2.8 COMPOUND QUANTIFICATION AND REPORTED DETECTION LIMITS $2-6$

$\begin{array}{lr}2.9 \text { SYSTEM PERFORMANCE ACCEPTABLE } & 2-7\end{array}$

2.10 CHANGES MADE SINCE PRELIMINARY REPORT 2-7

3.0 ISOTOPIC URANIUM DETERMINATION DATA VALIDATION AND LIMITATIONS 3-1

3.1 SUMMARY 3-1

3.1.1 Five Sample Delivery Groups $3-1$

3.1.2 All Samples Validated 3-1

3.1.3 Westinghouse Hanford Guidance Used 3-1

3.1.4 Data Quality Objectives Met 3-1

3.2 INSTRUMENT CALIBRATION ACCEPTABLE $3-2$

3.3 ACCURACY ACCEPTABLE 3-2

3.4 PRECISION GENERALLY ACCEPTABLE
$3-2$

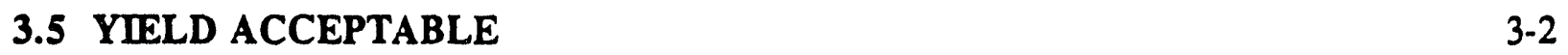

3.6 RADIONUCLIDE QUANTIFICATION AND REPORTED DETECTION LIMITS

3.7 SYSTEM PERFORMANCE ACCEPTABLE $3-3$

3.8 DATA QUALIFIERS CHANGED FROM PRELIMINARY REPORT 3-3

4.0 TOTAL URANIUM DETERMINATION

DATA VALIDATION AND LIMITATIONS 4-1

4.1 SUMMARY 4-1

4.1.1 Five Sample Delivery Groups 4-1

4.1.2 All Samples Validated 4-1 
CONTENTS (Continued)

Page

4.1.3 Westinghouse Hanford Guidance Used 4-1

4.1.4 Data Quality Objectives Generally Met 4-1

4.2 INSTRUMENT CALIBRATION ACCEPTABLE .

4.3 ACCURACY ACCEPTABLE $4-2$

4.4 PRECISION GENERALLY ACCEPTABLE 4-2

4.5 RADIONUCLIDE QUANTIFICATION AND REPORTED DETECTION LIMITS ACCEPTABLE

4.6 SYSTEM PERFORMANCE ACCEPTABLE 4-3

4.7 DATA QUALIFIERS CHANGED FROM PRELIMINARY REPORT 4-3

5.0 REFERENCES 5-1

TABLES

1-1 300-FF-5 Operable Unit Remedial Investigation $1-3$ Round 6 Groundwater Summary of Validated Samples

1-2 Glossary of Data Qualifiers

2-1 300-FF-5 Operable Unit Remedial Investigation $\quad 2-8$ Round 6 Groundwater Volatile Organic Compounds Analysis and Qualifier Summary

3-1 300-FF-5 Operable Unit Remedial Investigation $3-4$ Isotopic Uranium Analysis and Qualifier Summary

4-1 300-FF-5 Operable Unit Remedial Investigation 4-4 Total Uranium Analysis and Qualifier Summary 


\section{ACRONYMS}

$\% \mathrm{D}$

BFB

CLP

CRDL

CRQL

DOE

EPA

GC/MS

IDL

MDA

MS/MSD

NIST

PQAR

QA

QC

RPD

RRF

RSD

SOW

TIC

TMA

VOC

Weston

WHC percent difference

bromofluorobenzene

contract laboratory program

contract required detection limit

contract required quantitation limit

Department of Energy

U.S. Environmental Protection Agency

gas chromatography/mass spectrometry

instrument detection limit

minimal detectable amount

matrix spike/matrix spike duplicate

Natural Institute of Standards and Testing

preliminary quality assurance report

quality assurance

quality control

relative percent difference

relative response factor

relative standard deviation

statement of work

tentatively identified compound

Thermo Analytical Laboratories

volatile organic compound

Roy F. Weston Company

Westinghouse Hanford Company 


\subsection{INTRODUCTION}

Laboratory data for Sixth Round Groundwater samples collected during the 300-FF-5 Operable Unit Remedial Investigation have been reviewed and validated to ensure that they are of sufficient quality to support decisions regarding further actions to be taken at the 300FF-5 Operable Unit. Table $1-1$ is a summary of the validated samples. This report summarizes the results previously presented to Westinghouse Hanford in a series of Preliminary Quality Assurance Reports (PQAR) for the 300-FF-5 Sixth Round Groundwater samples. In some instances, the data qualifiers originally presented in the PQARs have been changed based upon further review of the data; these changes are highlighted in the text.

Throughout this report, various standard abbreviations have been used to note the qualifications associated with sample results. These abbreviations are summarized in Table $1-2$.

\subsection{CHEMICAL ANALYSES}

Data from the chemical analysis of 24 samples from the 300-FF-5 Operable Unit and their related quality assurance (QA) samples were reviewed and validated to verify that reported sample results were of sufficient quality to support decisions regarding remedial actions performed at this site. Four analytical cases were analyzed by Thermo Analytical Laboratories (TMA) and two were analyzed by Roy F. Weston (Weston) Laboratories for volatile organic compounds (VOC) using U.S. Environmental Protection Agency (EPA) Contract Laboratory Program (CLP) Statement of Work (SOW) (1990).

\subsection{RADIOCHEMICAL ANALYSES}

Data from three radiochemical cases analyzed by TMA and two cases analyzed by Weston were validated. Sample analyses included the following:

- Isotopic uranium (17 water samples); and

- Total uranium (34 water samples).

\subsection{WESTINGHOUSE HANFORD GUIDANCE USED}

Data quality was reviewed and analytical results were validated using Westinghouse Hanford procedures (WHC 1992a and 1992b). Data were qualified based on their quality and the guidance provided by these sources. 
WHC-SD-EN-TI-173, Rev. 0

\subsection{MAJOR DEFICIENCIES}

No analytical results were rejected due to deficiencies in data quality:

Volatile Organic Analyses. No sample data were rejected due to deficiencies in data quality.

Radiochemical Analysis. No sample data were rejected due to deficiencies in data quality.

\subsection{GENERAL QUALITY TRENDS}

Several general quality trends, which resulted in data qualification, were observed. These include the following:

- Acetone and methylene chloride were detected in one of the volatile organics method blanks.

- Two samples were reported to have air bubbles in all of the sample VOA vials. 
WHC-SD-EN-TI-173, Rev. 0

Table 1-1. 300-FF-5 Operable Unit Remedial Investigation

Round 6 Groundwater

Summary of Validated Samples

\begin{tabular}{|c|c|c|c|}
\hline Sample & $\begin{array}{c}\text { Volatile } \\
\text { Organic } \\
\text { Compounds }\end{array}$ & $\begin{array}{l}\text { Isotopic } \\
\text { Uranium }\end{array}$ & $\begin{array}{c}\text { Total } \\
\text { Uranium }\end{array}$ \\
\hline B095J 1 & $\mathrm{x}$ & $\mathbf{x}$ & $\mathrm{x}$ \\
\hline B095M5 & $x$ & $x$ & $\mathbf{x}$ \\
\hline B095M 8 & $Y$ & - & - \\
\hline B095K7 & $X$ & $\mathrm{X}$ & $x$ \\
\hline B095K2 & $Y$ & $\mathrm{x}$ & $\mathbf{x}$ \\
\hline B095K8 & $Y$ & $x$ & $\mathbf{x}$ \\
\hline B095L4 & $Y$ & $x$ & $x$ \\
\hline B095L5 & $Y$ & $x$ & $X$ \\
\hline B095M6 & $Y$ & - & - \\
\hline B095JO & $Y$ & $x$ & $x$ \\
\hline B095K0 & $\mathrm{x}$ & $x$ & $\mathbf{x}$ \\
\hline B095K 1 & $Y$ & $x$ & $x$ \\
\hline B095K9 & $Y$ & $\mathrm{x}$ & $x$ \\
\hline B095M3 & $Y$ & $\mathrm{x}$ & $x$ \\
\hline B095M7 & $Y$ & -- & - \\
\hline B095J5 & $\mathbf{Y}$ & $\mathrm{x}$ & $x$ \\
\hline B095J 6 & $Y$ & - & - \\
\hline B095K6 & $Y$ & $\mathrm{x}$ & $x$ \\
\hline B095L9 & $\mathrm{Y}$ & $x$ & $x$ \\
\hline B095LO & $x$ & $\mathbf{X}$ & $\mathbf{X}$ \\
\hline B095M4 & $Y$ & $x$ & $\mathbf{x}$ \\
\hline B095M9 & $Y$ & - & - \\
\hline B095N1 & $Y$ & -- & - \\
\hline B095N2 & $Y$ & -- & - \\
\hline B095J7 & - & - & $\mathrm{x}$ \\
\hline B095J8 & -- & -- & $x$ \\
\hline B095J9 & -- & - & $\mathbf{x}$ \\
\hline B095MO & -- & - & $\mathbf{X}$ \\
\hline B095M1 & -- & - & $x$ \\
\hline B095M2 & - & - & $\mathbf{X}$ \\
\hline B095L1 & - & - & $\mathbf{X}$ \\
\hline B095L2 & - & - & $x$ \\
\hline B095L3 & - & -- & $\mathrm{x}$ \\
\hline B095K 4 & - & - & $\mathbf{x}$ \\
\hline B095K5 & - & - & $\mathrm{x}$ \\
\hline B095L6 & - & - & $\mathrm{x}$ \\
\hline B095L7 & - & - & $\mathbf{X}$ \\
\hline B095J2 & - & -- & $\mathbf{X}$ \\
\hline B095J3 & -- & - & $\mathbf{x}$ \\
\hline B095J 4 & - & - & $\mathbf{x}$ \\
\hline
\end{tabular}

$X=$ Level IV validation.

$Y=$ Level II validation.

-- Analyzed for, but not validated.

Jonerzensolow6TI-1.w1 
WHC-SD-EN-TI-173, Rev. 0

\section{Table 1-2. Glossary of Data Qualifiers}

$\mathbf{U}$ Indicates the compound or analyte was analyzed for and not detected. The value reforted is the sample quantitation limit corrected for sample dilution and moisture content by the laboratory.

UJ Indicates the compound or analyte was analyzed for and not detected. Due to quality control deficiencies identified during data validation the value reported may not accurately reflect the sample quantitation limit.

J Indicates the compound or analyte was analyzed for and detected. The associated value is estimated but the data are useable for decision making processes.

$\mathbf{R}$ Indicates the compound or analyte was analyzed for and due to an identified quality control deficiency the data are not useable.

JN Indicates presumptive evidence of a compound at an estimated value. 


\subsection{VOLATILE ORGANIC DATA VALIDATION AND LIMITATIONS}

\subsection{SUMMARY}

\subsubsection{Six Sample Delivery Groups}

Sample results from six volatile organic cases are included in this report:

\begin{tabular}{cccc}
\hline Laboratory & $\begin{array}{c}\text { Case } \\
\text { Number }\end{array}$ & $\begin{array}{c}\text { No. of } \\
\text { Samples }\end{array}$ & $\begin{array}{c}\text { No. Fully } \\
\text { Validated }\end{array}$ \\
\hline TMA & A309082 & 6 & 1 \\
TMA & A309049 & 5 & 1 \\
TMA & A310001 & 4 & 0 \\
TMA & A309074 & 6 & 1 \\
Weston & 9309 L093 & 2 & 1 \\
Weston & 9309 L018 & 1 & 1 \\
\hline
\end{tabular}

Table 2-1.

Data qualifiers assigned to the sample data for these cases are summarized in

\subsubsection{All Samples Validated}

Results for all the sample analyses for the cases listed above were validated, and data qualifiers assigned as appropriate. All of the reported results for quality assurance samples associated with these cases were reviewed. For all cases, one hundred percent of the quality assurance sample results were recalculated and quality control calculations verified. A limited number of samples, specified by Westinghouse Hanford, were fully validated (i.e., all sample results were recalculated from the laboratory raw data).

\subsubsection{Westinghouse Hanford Validation Guidance Used}

Data validation was performed in accordance with the Westinghouse Hanford/Data Validation Procedures for Chemical Analyses (WHC 1992a).

\subsubsection{Samples Analyzed According to CLP Protocols}

Twenty-four low level water samples were submitted for analysis. Analyses were performed according to the 1990 CLP protocol (EPA 1990). Failure to comply with various technical requirements established by CLP protocols resulted in qualification of the data. 
WHC-SD-EN-TI-173, Rev. 0

The specific problems observed during the quality assurance review are detailed in the sections below.

The analyses were complete and met the method and work plan CRQL (DOE 1990) in all cases.

\subsubsection{Minor Deficiencies Noted}

There were minor deficiencies associated with the analyses, which resulted in the qualification of data. These included: minor blank contamination, sample concentrations reported below the CRQL, and air bubbles found in the VOA vials. These deficiencies and the resulting data qualifications are explained in greater detail below.

\subsection{ANALYTICAL METHOD}

\subsubsection{Gas Chromatography/Mass Spectrometer (GC/MS) Tuning Criteria Met}

Tuning is performed to ensure that mass resolution, identification, and, to some degree, sensitivity of the GC/MS instrument have been established. When analyzing for volatile organics, instrument tuning is performed with bromofluorobenzene (BFB). Instrument tuning must be performed prior to the analysis of either standards or samples and must meet the criteria established by the analytical protocol. The specific criteria for acceptable GC/MS instrument tuning using BFB are outlined in the Westinghouse Hanford data validation guidelines (WHC 1992a) and in the CLP SOW (EPA 1990).

All tuning and mass calibration summary forms (Form V) were evaluated to verify that tuning criteria were met. In addition, the original tuning data were checked for transcription and calculation errors in one of the packages. Prior to calibration and sample analysis, all tuning criteria were met and no data were qualified based on the tuning results.

\subsubsection{Acceptable Calibration}

Instrument calibration is performed to establish that the GC/MS instrument is capable of producing acceptable and reliable analytical data over a range of concentrations. The initial and continuing calibrations are to be performed according to CLP protocols. An initial multipoint calibration is performed prior to sample analysis to establish the linear range of the GC/MS instrument. Continuing calibration checks are performed to verify that instrument performance is stable and reproducible during analytical runs.

A detailed description of the results of the initial and. continuing calibrations performed is presented below. 


\subsubsection{No Initial Calibration Exceedences}

Instrument response is established when the relative response factors (RRFs) for all target compounds are greater than or equal to the minimum criteria specified in the CLP SOW (EPA 1990). Linearity is established when the relative standard deviations (RSDs) of the RRFs are less than or equal to 20.5 percent (EPA 1990). Only some of the compounds are required to meet these criteria, and minor exceedences of common problem compounds do not cause qualification of the data.

For each of the cases, the initial calibrations met the criteria. Therefore, no data were qualified based on the initial calibration results.

\subsubsection{No Continuing Calibration Exceedences}

The criteria for accepting the continuing calibration require that a $50 \mu \mathrm{g} / \mathrm{L}$ standard be analyzed at least once per 12-hour period and that the RRFs of all target compounds be greater than or equal to the minimum criteria specified in the CLP SOW (EPA 1990). In addition, the percent difference (\%D) of these RRFs must be less than or equal to 25 percent (EPA 1990) of the average RRFs calculated from the associated initial calibration. Only some of the compounds are required to meet these criteria, and minor exceedences of common problem compounds do not cause qualification of the data.

The required analysis frequency and criteria for continuing calibration were met for these cases, and no data were qualified based on the continuing calibration results.

\subsubsection{Blanks}

Method blank and field blank analyses are performed to determine the extent of laboratory or field contamination of samples. If the sample concentration for a compound is less than five times the blank concentration (ten times if the compound is a common laboratory contaminant), the sample concentration is qualified as undetected (U).

\subsubsection{Minor Method Blank Contamination}

One method blank was analyzed during each 12-hour period, on each instrument. Methylene chloride was detected in one of the blanks at low concentrations. Associated sample data were qualified as outlined below.

Case A309082. No target compounds were detected in the method blank associated with this case.

Case A309049. No target compounds were detected in the method blank associated with this case.

Case A309074. No target compounds were detected in the method blank associated with this case. 
WHC-SD-EN-TI-173, Rev. 0

Case A310001. No target compounds were detected in the method blank associated with this case.

Case 9302L748. No target compounds were detected in the method blank associated with this case.

Case 9309L093. Acetone and methylene chloride were detected in the method blank associated with this case. The acetone and methylene chloride concentrations for samples B095M5 and B095M8 were less than 10 times the concentration reported for the blank; therefore, acetone and methylene chloride were qualified as undetected $(U)$ at the CRQL.

\subsubsection{Air Bubbles Found in Two Samples}

It was reported that air bubbles were found in all three of the submitted VOA vials for two samples (B095M6 and B095M7). Therefore, all volatile compounds for these two samples were qualified as estimates $(J$ ) for detects and estimated quantitation limits (UJ) for non-detects.

\subsection{HOLDING TIMES}

Analytical holding times were assessed to ascertain whether the CLP holding time requirements for volatile organic analyses were met by the laboratory. The CLP holding time requirements for volatile organic analyses are as follows: water samples must be analyzed within 14 days of the date of sample collection; and all samples must be shipped on ice to the laboratory and stored at $4^{\circ} \mathrm{C}$ until analysis.

The holding times were acceptable for all of the samples associated with these six cases. Therefore, no qualifiers were assigned based on the holding time.

\subsection{ACCURACY}

Accuracy was assessed by evaluating the recoveries of stable isotopically labeled surrogate compounds added to all samples and blanks, matrix spikes, and by the analysis of a representative sample, which was spiked with a variety of volatile organic compounds.

\subsubsection{Surrogate Compound Recovery Acceptable}

Matrix-specific surrogate compound recovery control windows have been established by the EPA CLP (EPA 1990). When a surrogate compound recovery is out of the control window, all positively identified target compounds associated with the unacceptable surrogate recoveries are qualified as estimates (J). Undetested compounds are qualified as having an estimated detection limit (UJ). The surrogate compound recoveries calculated for the three stable isotopically labeled surrogate compounds were acceptable for each sample. Therefore, no qualifiers were assigned based on surrogate recovery. 
WHC-SD-EN-TI-173, Rev. 0

\subsubsection{Matrix Spike Recoveries Acceptable}

Matrix spike compounds are added to a sample, which is representative of the sample delivery group. Matrix spike analyses are performed in duplicate using five compounds specified by CLP protocols. The recoveries for the five compounds must be within the sample matrix established quality control limits (EPA 1990). The matrix spike analyses estimate the interference with target compounds, either positively or negatively.

Six matrix spike (MS) samples and six matrix spike duplicate (MSD) samples were analyzed with the cases addressed in this report. The matrix spike compound recoveries were acceptable. Therefore, no qualifiers were assigned based on matrix spike percent recoveries.

\subsection{PRECISION ACCEPTABLE}

Analytical precision is expressed by the RPD between the recoveries of duplicate matrix spike analyses performed on a sample. When the laboratory has not performed MS/MSD analyses, precision may also be assessed using unspiked duplicate sample analyses. Field precision is measured by analyzing duplicate samples taken in the field. Interlaboratory precision is measured by analyzing duplicate samples ("field splits") by two analytical laboratories.

\subsubsection{Matrix Spike Duplicates Acceptable}

Six water MSD samples were analyzed with the cases addressed in this report. The MSD RPDs were acceptable for all six cases. Therefore, no qualifiers were assigned based on the MSD precision.

\subsubsection{Field Duplicates Acceptable}

Two sets of field duplicates were submitted for analysis (B095K7/B095K8 and B095L4/B095L5). Acetone, chloroform, and trichloroethene were detected at concentrations less the CRQL. Therefore, field precision could not be quantitatively evaluated. No qualifiers were required based on field precision.

\subsubsection{Split Samples Acceptable}

Two sets of split samples (B095L0/B095J1 and B095J0/B095M5) were submitted for analysis. No target compounds were detected in split set B095J0/B095M5. Methylene chloride, chloroform, and trichloroethene were detected in split set B095L0/B095J1 at concentrations less than the CRQL. Therefore, interlaboratory precision could not be quantitatively evaluated. No qualifiers were assigned to any of the split samples based on interlaboratory precision. 


\subsection{INTERNAL STANDARD PERFORMANCE ACCEPTABLE}

Internal standard performance was assessed to determine whether abrupt changes in instrument response and sensitivity occurred that may have affected the reliability of the analytical data. The response (area or height) of the internal standards must not vary by more than +100 percent or -50 percent from the response of the internal standard that was used to calculate the upper and lower bounds. The upper and lower bounds define the range for acceptable internal standard response (area/height) for the sample analyses. The criteria for internal standard performance were met for all samples.

\subsection{IDENTIFICATION OF COMPOUNDS}

The identity of detected compounds was confirmed by investigating the possibility of false positives. The confirmation of compound identification during the quality assurance review focuses on false positives because only mass spectra for positive identifications are submitted. Confirmation of possible false negatives is addressed by reviewing other factors relating to analytical sensitivity (e.g., relative response factors, detection limits, linearity, and analytical recovery).

The validator confirmed the compound identifications. Trace concentrations of acetone, methylene chloride, chloroform, and trichloroethene were reported in several of the samples. Methylene chloride and acetone are common laboratory contaminants, and affected sample concentrations were qualified due to contamination of one of the blanks. Chloroform and trichloroethene were not detected in the method blank associated with the samples; therefore, the data were not qualified as undetected. However, at these low concentrations, the source of the methylene chloride, chloroform, and trichloroethene cannot be confirmed to be the site.

All tentatively identified compounds (TICs) that were detected in the method blank and its associated sample were qualified as undetected (U). All other TICs that were detected in the sample but not in the method blank were qualified as presumptively identified at estimated concentrations (JN).

\subsection{COMPOUND QUANTIFICATION AND REPORTED DETECTION LIMITS}

Compound quantifications and reported detection limits were recalculated for the samples specified by Westinghouse Hanford for each case to verify that they were accurate and consistent with CLP requirements. The calculations were consistent with the reported results. Therefore, no changes or qualifications were made based on the calculations.

Below the CRQL, instrument precision becomes more variable as the instrument detection limit (IDL) is approached. Therefore, the concentration of any compound that was detected below the CRQL was qualified as an estimate (J). 
WHC-SD-EN-TI-173, Rev. 0

\subsection{SYSTEM PERFORMANCE ACCEPTABLE}

A thorough review of ongoing data acquisition and instrument performance criteria was made to assess overall GC/MS instrument performance. No changes in instrument performance were noted that would result in the degradation of data quality. No indications of unacceptable instrument performance (i.e., shifts in baseline stability, retention time shifts, extraneous peaks, sensitivity) were found during the quality assurance review.

\subsection{CHANGES MADE SINCE PRELIMINARY REPORT}

The results for sample B095M7 were not initially qualified due to the presence of air bubbles being found in the sample vials. The Form I was corrected and the associated data table was revised. 
Table 2-1. 300-FF-S Operable Una Remodill Inveatigntion

Round 6 Groundweter Volatile Orgenic Compounds

Analyais and Qualificer Summary

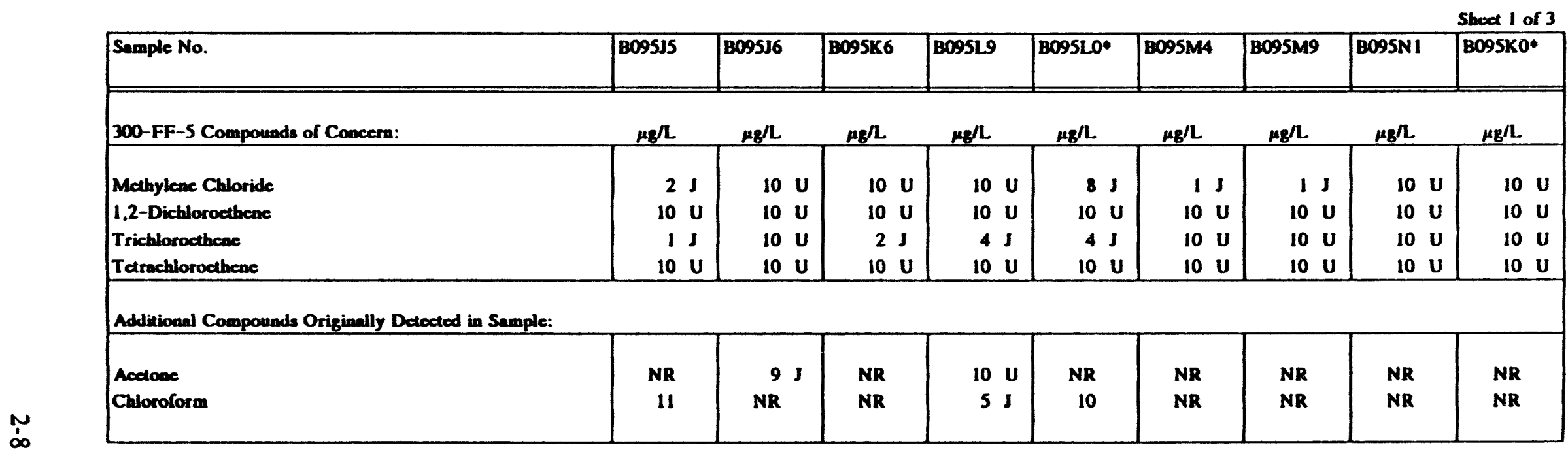

NR - not reported as detocted

- - fully validalod sample 
Table 2-1. 300-FF-5 Operebis Unir Reanodiel Invedigation

Round 6 Gromedweter Volentite Organic Compounde

Analyais and Qualificer Summary

\begin{tabular}{|c|c|c|c|c|c|c|c|c|c|}
\hline & & & & & & & & & Sboet 2 of 3 \\
\hline Semple No. & BogsK 1 & Bossk9 & B095M3 & BO95M7 & B095K8 & BOOSLA & B0951.5 & B095M6 & BOSSJ0 \\
\hline 300-FF-5 Componade of Concern: & $\mu g / L$ & $\mu_{g} / L$ & $\mu g / L$ & rg $h$ & $\mu g / L$ & $\mu g / L$ & $\mu g / 2$ & $\mu g / L$ & $\mu \mathrm{g} / \mathrm{L}$ \\
\hline Methylene Chloride & $10 \mathrm{U}$ & $10 \mathrm{U}$ & $10 \mathrm{U}$ & $\begin{array}{ll}10 & \mathrm{U}\end{array}$ & $10 \mathrm{U}$ & $10 \mathrm{U}$ & $10 \mathrm{U}$ & $\begin{array}{ll}10 & \mathrm{UJ}\end{array}$ & $10 \mathrm{U}$ \\
\hline 1.2-Dichloroctbene & $10 \mathrm{U}$ & $10 \mathrm{U}$ & $10 \mathrm{U}$ & $10 \mathrm{UJ}$ & $10 \mathrm{U}$ & $10 \mathrm{U}$ & $10 \mathrm{U}$ & $10 \mathrm{UJ}$ & $10 \mathrm{U}$ \\
\hline Trichlorocthese & $1 \mathrm{~J}$ & $4 J$ & $3 \mathbf{U}$ & $10 \mathrm{UJ}$ & $2 J$ & $2 J$ & $2 J$ & $10 \mathrm{UJ}$ & $10 \mathrm{U}$ \\
\hline Tetruchloroethene & $10 \mathrm{U}$ & $10 \mathrm{U}$ & $10 \mathrm{U}$ & $10 \mathrm{UJ}$ & $10 \mathrm{U}$ & $10 \mathrm{U}$ & $10 \mathrm{U}$ & $10 \mathrm{UJ}$ & $10 \mathrm{U}$ \\
\hline \multicolumn{10}{|c|}{ Additional Compounda Origimally Detected in Sample: } \\
\hline Acetone & NR & NR & NR & NR & $9 \mathrm{~J}$ & NR & $6 \mathrm{~J}$ & $10 \mathrm{Us}$ & NR \\
\hline Chloroform & 23 & $1 \mathrm{~J}$ & NR & NR & 11 & $2 J$ & $2 \mathrm{~J}$ & $10 \mathrm{Us}$ & NR \\
\hline
\end{tabular}

NR - nol reported as detoctod

- - fully validatod sample 
Toble 2-1. 300-FF-5 Opexble Unil Remodiel Imvetigntion

Round 6 Cromedweter Volntillo Orgenic Compounde

Anbyis and Quilifier Sumenary

\begin{tabular}{|c|c|c|c|c|c|c|}
\hline Semple No. & Bogsj1* & BO95M5* & Bogsm: & Bos5K 7* & BOS5K2 & BogsN2 3 of 3 \\
\hline 300-FF-5 Compounde of Comocern: & mg/L & men & $\mathrm{mg} / \mathbf{L}$ & $\mu g / \mathbf{L}$ & $\mu g \Omega$ & $\mu \& \Omega$ \\
\hline $\begin{array}{l}\text { Methylene Chlaride } \\
\text { 1.2-Dichlorocthene } \\
\text { Trichlonocthene } \\
\text { Tarechlorocthene }\end{array}$ & $\begin{array}{rl}10 & U \\
10 & U \\
5 & J \\
10 & U\end{array}$ & $\begin{array}{ll}10 & U \\
10 U \\
10 U \\
10 U\end{array}$ & $\begin{array}{ll}10 & \mathrm{U} \\
10 \mathrm{U} \\
10 \mathrm{U} \\
10 \mathrm{U}\end{array}$ & $\begin{array}{rl}10 & U \\
10 & U \\
2 & J \\
10 & U\end{array}$ & $\begin{array}{ll}10 U \\
10 U \\
10 U \\
10 U\end{array}$ & $\begin{array}{ll}10 & U \\
10 & U \\
10 & U \\
10 & U\end{array}$ \\
\hline \multicolumn{7}{|c|}{ Additioned Compounds Origionlly Detocted in Sample: } \\
\hline $\begin{array}{l}\text { Acctowe } \\
\text { Chloroform }\end{array}$ & $\begin{array}{l}10 \mathrm{U} \\
11\end{array}$ & $\begin{array}{l}10 \mathrm{U} \\
\text { NR }\end{array}$ & $\begin{array}{l}10 \mathrm{U} \\
\mathrm{NR}\end{array}$ & $\begin{array}{r}\text { NR } \\
12\end{array}$ & $\begin{array}{c}\text { NR } \\
8 \mathrm{~J}\end{array}$ & $\begin{array}{l}\text { NR } \\
\text { NR }\end{array}$ \\
\hline
\end{tabular}

NR - wot reported as detocted

- - fully validetod empiple 


\subsection{ISOTOPIC URANIUM DETERMINATION DATA \\ VALIDATION AND LIMITATIONS}

\subsection{SUMMARY}

\subsubsection{Five Sample Delivery Groups}

Sample results for isotopic uranium analyses for the five radiochemistry cases listed below are included in this report.

\begin{tabular}{ccccc}
\hline Laboratory & Case Number & $\begin{array}{c}\text { No. of } \\
\text { Samples }\end{array}$ & $\begin{array}{c}\text { No. Samples } \\
\text { Analyzed for } \\
\text { Isotopic Uranium }\end{array}$ & Water/Soil \\
\hline TMA & N3-09-066-7245 & 13 & 4 & Water \\
TMA & N3-09-124-7264 & 18 & 10 & Water \\
TMA & N3-09-151-7268 & 1 & 1 & Water \\
Weston & $9309 L 018$ & 1 & 1 & Water \\
Weston & $9309 L 093$ & 1 & 1 & Water \\
\hline
\end{tabular}

All samples were fully validated. Data qualifiers assigned to the isotopic uranium results for these cases, including uranium-234 $\left({ }^{34} \mathrm{U}\right)$, uranium-235 $\left({ }^{35} \mathrm{U}\right)$, and uranium-238 $\left.{ }^{23 t} \mathrm{U}\right)$, are summarized in Table $3-1$.

\subsubsection{All Samples Validated}

Analytical data for all of the samples analyzed for isotopic uranium in the cases listed above were reviewed and data qualifiers assigned as appropriate. One hundred percent of the sample results, including the quality assurance sample results, were recalculated. In addition, quality control calculations were verified for all sample delivery groups.

\subsubsection{Westinghouse Hanford Guidance Used}

Data were validated in accordance with the Westinghouse Hanford Data Validation Procedure for Radiological Analyses (WHC 1992b).

\subsubsection{Data Quality Objectives Met}

All data quality objectives were met. The precision of one sample could not be evaluated due to sample results less than the minimum detectable amount (MDA). 


\subsection{INSTRUMENT CALIBRATION ACCEPTABLE}

Instrument calibration was performed at TMA and Weston to establish that the alpha spectroscopy system used for isotopic uranium determination is capable of producing acceptable and reliable analytical data. The initial calibration was performed according to the manufacturer's recommendations and consisted of determining the instrument detection efficiency for each alpha energy, system resolution, and the full-width at half maximum for each peak. In addition, the isotopic uranium method employs the addition of a National Institute of Standards and Testing (NIST) traceable uranium-232 $\left({ }^{232} \mathrm{U}\right)$ internal reference standard. Continuing calibration checks are performed to verify that instrument performance is stable and reproducible on a day to day basis. Calibrations were acceptable for all cases.

\subsection{ACCURACY ACCEPTABLE}

Accuracy was evaluated by analyzing samples spiked with known amounts of uranium isotopes. The sample activity as determined by sample analysis is compared to the known activity to assess method accuracy. The analytical result must be within 80 to 120 percent of the true value to be deemed acceptable. Data for samples with spiked sample results outside this range are qualified as estimated (J or UJ) or rejected (R).

Accuracy was acceptable for all sample results.

\subsection{PRECISION GENERALLY ACCEPTABLE}

Analytical precision is expressed as the RPD between the recoveries of duplicate matrix spike analyses performed on a single sample. When the laboratory has not performed duplicate spike analyses, precision may be assessed using unspiked samples provided that the analyte activity is greater than the MDA. If the analyte activity is less than the MDA for either the original or duplicate sample, precision cannot be determined. The control limit defining acceptable precision is an RPD of less than 35 percent for replicates with activity levels five times the MDA or greater. If the activity of either replicate sample is less than five times the MDA, the difference between the two replicate values must be less than two times the MDA.

Precision was generally acceptable for all sample results. Precision could not be evaluated for sample B095M4 due to the original or duplicate analysis less than the MDA. No data qualifiers were assigned to this sample.

\subsection{YIELD ACCEPTABLE}

The yield is a numerical factor that compensates for sample losses during separation, dissolution, leaching, or purification. The yield is typically determined by the addition of a compound that has similar chemical properties to the analytes of concern but is either 
analyzed at a different energy or by a different method. Yields must be within the control limits of $30-105 \%$. Results below this range are rejected (R). Results above this range are qualified as estimated ( $J$ or UJ) for yields up to $115 \%$ or rejected (R) for yields greater than $115 \%$. If the sample activity is greater than four times the spike activity, recovery limits do not apply.

The yields for all sample results were acceptable.

\subsection{RADIONUCLIDE QUANTIFICATION AND REPORTED DETECTION LIMITS}

Radionuclide quantifications and detection limits were recalculated for all samples in each data package to verify that they are accurate and consistent with Westinghouse Hanford requirements. Results below the MDA were qualified as nondetects (U).

The quantification and detection limits were acceptable. Samples B095L5, B095K0, B095M3, and B095M4 had results less than the MDA, and were qualified as nondetects (U).

\subsection{SYSTEM PERFORMANCE ACCEPTABLE}

A review of TMA and Weston instrument continuing calibration information and QAVC data indicates that instrument performance was adequate for these analyses.

\subsection{DATA QUALIFIERS CHANGED FROM PRELIMINARY REPORT}

In the preliminary quality assurance reports, the sample results for four samples (B095K6, B095J5, B095L0, and B095L9) were rejected (R) due to lack of traceability of the

${ }^{232} \mathrm{U}$ source. Traceability information has since been provided by the laboratory; therefore, these data are no longer rejected. 
Table 3-1. 300-FF-5 Operable Unit Remedial Investigation/Feasibility Study Isotopic Uranium Analysis and Qualifier Summary

\begin{tabular}{|c|c|c|c|c|c|c|}
\hline \multirow[b]{2}{*}{$\begin{array}{l}\text { Customer } \\
\text { I.D. No. }\end{array}$} & \multicolumn{2}{|c|}{ Uranium 233/234 } & \multicolumn{2}{|c|}{ Uranium 235} & \multicolumn{2}{|c|}{ Uranium 238} \\
\hline & $\begin{array}{c}\text { Reported } \\
\text { Results } \\
\text { in } \mathrm{PC} / \mathrm{L}\end{array}$ & Qualifier & $\begin{array}{l}\text { Reported } \\
\text { Results } \\
\text { in pCi } / \mathrm{L}\end{array}$ & Qualifier & $\begin{array}{l}\text { Reported } \\
\text { Results } \\
\text { in } \mathrm{pCi} / \mathrm{L}\end{array}$ & Qualifier \\
\hline \multicolumn{7}{|c|}{ TMA Norcal Case N3-09-066-7245 } \\
\hline B095K6 & 6.70 & & 0.55 & & 8.70 & \\
\hline B095J5 & 45.00 & & $\therefore 70$ & & 33.00 & \\
\hline BO9SLO & 14.00 & & 1.40 & & 13.00 & \\
\hline BO95L9 & 7.50 & & 0.55 & & 7.70 & \\
\hline \multicolumn{7}{|c|}{ TMA Norcal Case N3-09-124-7264 } \\
\hline B095K2 & 41.00 & & 6.30 & & 30.00 & \\
\hline B095K7 & 9.70 & & 0.52 & & 8.40 & \\
\hline B095K8 & 3.50 & & 0.28 & & 3.60 & \\
\hline B095L4 & 22.00 & & 2.10 & & 23.00 & \\
\hline B095L5 & 27.00 & & 0.86 & $U$ & 25.00 & \\
\hline B095JO & 30.00 & & 4.10 & & 21.00 & \\
\hline B095KO & 0.11 & U & -0.01 & U & 0.14 & \\
\hline B095Kd & 11.00 & & 1.10 & & 9.10 & \\
\hline B095K9 & 12.00 & & 0.74 & & 11.00 & \\
\hline B095M3 & 0.10 & U & 0.10 & $\mathrm{U}$ & 0.08 & $\mathrm{U}$ \\
\hline \multicolumn{7}{|c|}{ TMA Norcal Case N3-09-151-7268 } \\
\hline B095M4 & 0.02 & $\mathrm{U}$ & -0.02 & $\mathrm{U}$ & 0.01 & $\mathrm{U}$ \\
\hline \multicolumn{7}{|c|}{ Weston Case 9309L018 } \\
\hline B095J1 & 15.00 & & 0.44 & & 15.00 & \\
\hline \multicolumn{7}{|c|}{\begin{tabular}{|l} 
Weston Case 9309L093 \\
\end{tabular}} \\
\hline B095M5 & 33.00 & & 1.20 & & 25.00 & \\
\hline
\end{tabular}

2omsolgw63-1.wk! 


\subsection{TOTAL URANIUM DETERMINATION \\ DATA VALIDATION AND LIMITATIONS}

\subsection{SUMMARY}

\subsubsection{Five Sample Delivery Groups}

Sample results for total uranium analyses for the five radiochemistry cases listed below are included in this report.

\begin{tabular}{ccccc}
\hline Laboratory & Case Number & $\begin{array}{c}\text { No. of } \\
\text { Samples }\end{array}$ & $\begin{array}{c}\text { No. Samples } \\
\text { Analyzed for } \\
\text { Total Uranium }\end{array}$ & Water/Soil \\
\hline TMA & N3-09-066-7245 & 13 & 13 & Water \\
TMA & N3-09-124-7264 & 18 & 18 & Water \\
TMA & N3-09-151-7268 & 1 & 1 & Water \\
Weston & 9309 L018 & 1 & 1 & Water \\
Weston & 9309 L093 & 1 & 1 & Water \\
\hline
\end{tabular}

All samples were fully validated. Data qualifiers assigned to the total uranium results for these cases are summarized in Table 4-1.

\subsubsection{All Samples Validated}

Analytical data for all of the samples in the cases listed above were reviewed and data qualifiers assigned as appropriate. One hundred percent of the sample results, including the quality assurance sample results, were recalculated. In addition, quality control calculations were verified for all sample delivery groups.

\subsubsection{Westinghouse Hanford Guidance Used}

Data were validated in accordance with the Westinghouse Hanford Data Validation Procedure for Radiological Analyses (WHC 1992b).

\subsubsection{Data Quality Objectives Generally Met}

All data quality objectives that were met. The precision of two samples could not be evaluated due to sample results less than the MDA. 


\subsection{INSTRUMENT CALIBRATION ACCEPTABLE}

Instrument calibration is performed to establish that the method used for total uranium determination is capable of producing acceptable and reliable analytical data. TMA used the kinetic phosphorimetry analysis method and Weston used the laser fluorimetric method. For the kinetic phosphorimetry analysis, calibration is performed on a periodic basis to establish linearity of the comparison between a traceable weight concentration of uranium and the measured intensity of the phosphorescence due to laser excitation of the uranium. For laser fluorimetric analysis, calibration is performed on a periodic basis to establish linearity of the comparison between a traceable weight concentration of uranium and the measured intensity of the fluorescence due to laser excitation of the uranium. This concentration is converted to activity of total uranium based on a ${ }^{238} \mathrm{U}$ conversion factor. The calibration is performed according to the manufacturer's recommendations. Linearity and other parameters for each sample are compared to manufacturer's recommendations to ensure that the instrument is continuing to function properly.

No TMA or Weston data were qualified as a result of instrument calibration deficiencies.

\subsection{ACCURACY ACCEPTABLE}

Accuracy was evaluated by analyzing samples spiked with known amounts of uranium. The analyzed sample concentration is compared to the known concentration to assess method accuracy. The analytical result must be within 80 to 120 percent of the true value to be deemed acceptable. Data for samples with spiked sample results outside this range are qualified as estimates (J or UJ) or rejected (R).

Accuracy was acceptable for all samples.

\subsection{PRECISION GENERALLY ACCEPTABLE}

Analytical precision is expressed as the RPD between the recoveries of duplicate matrix spike analyses performed on a single sample. When the laboratory has not performed duplicate spike analyses, precision may be assessed using unspiked samples provided that the analyte activity is greater than the MDA. If the analyte activity is less than the MDA for either the original or duplicate sample, precision cannot be determined. The control limit defining acceptable precision is an RPD of less than 35 percent for replicates with activity levels five times the MDA or greater. If the activity of either replicate sample is less than five times the MDA, the difference between the two replicate values must be less than two times the MDA.

Precision was generally acceptable for all sample results. Precision could not be evaluated for sample B095M4 due to original or duplicate analysis results less than the MDA. No qualifiers were assigned to this sample. 
WHC-SD-EN-TI-173. Rev. 0

\subsection{RADIONUCLIDE QUANTIFICATION AND REPORTED DETECTION LIMITS ACCEPTABLE}

Radionuclide quantifications and detection limits were recalculated for all sample results in each data package to verify that they are accurate and consistent with Westinghouse Hanford requirements. Results below the MDA were qualified as nondetects (U).

The quantification and reported detection limits were acceptable. The sample results for samples B095M3 and B095M4 were less than the MDA and were qualified as nondetects (U).

\subsection{SYSTEM PERFORMANCE ACCEPTABLE}

A review of instrument continuing calibration information and QAVC data indicates that instrument performance for both TMA and Weston met established requirements.

\section{DATA QUALIFIERS CHANGED FROM PRELIMINARY REPORT}

There were no changes for total uranium validation results. 
Table 4-1. 300-FF-5 Operable Unit Remedial Investigation/Feasibility Study Total Uranium

Analysis and Qualifier Summery

\begin{tabular}{|c|c|c|}
\hline \multirow[b]{2}{*}{$\begin{array}{l}\text { Customer } \\
\text { I.D. No. }\end{array}$} & \multicolumn{2}{|c|}{ Total Uranium } \\
\hline & $\begin{array}{l}\text { Reported } \\
\text { Reoults } \\
\text { in pCi } / \mathrm{L}\end{array}$ & Qualifier \\
\hline \multicolumn{3}{|c|}{ TMA Norcal Case N3-09-066-7245 } \\
\hline B095K6 & 26.00 & \\
\hline BO95J5 & 96.00 & \\
\hline BO95J7 & 110.00 & \\
\hline B095J8 & 98.00 & \\
\hline B095J9 & 100.00 & \\
\hline BO9SLO & 41.00 & \\
\hline BOSSL9 & 25.00 & \\
\hline BO95MO & 24.00 & \\
\hline B095M1 & 24.00 & \\
\hline B095M2 & 25.00 & \\
\hline Bo95L1 & 46.00 & \\
\hline BO95L2 & 43.00 & \\
\hline BOSSL 3 & 42.00 & \\
\hline \multicolumn{3}{|c|}{ TMA Norcal Case N3-09-124-7264 } \\
\hline BO95K2 & 110.00 & \\
\hline BO95K4 & 100.00 & \\
\hline BO95K5 & 100.00 & \\
\hline B095K7 & 24.00 & \\
\hline B095K8 & 27.00 & \\
\hline BOS5L4 & 70.00 & \\
\hline Bossts & 70.00 & \\
\hline B09SL6 & 52.00 & \\
\hline BO9SL7 & 61.00 & \\
\hline BO95JO & 70.00 & \\
\hline $\mathrm{BOSSJ2}$ & 78.00 & \\
\hline BogsJ3 & 51.00 & \\
\hline B095J4 & 71.00 & \\
\hline BO95KO & 88.00 & \\
\hline B095K1 & 0.68 & \\
\hline BO95KO & 33.00 & \\
\hline B095M3 & 0.04 & U \\
\hline \multicolumn{3}{|c|}{ TMA Noreal Case N3-09-151-7268 } \\
\hline $\mathrm{B} 095 \mathrm{M} 4$ & 0.04 & $\mathrm{U}$ \\
\hline \multicolumn{3}{|c|}{ Weston Case 9309L018 } \\
\hline B095JI & 36.00 & \\
\hline \multicolumn{3}{|c|}{ Weston Case 9309L093 } \\
\hline B095M5 & 59.00 & \\
\hline
\end{tabular}

20nsovowg-1, wte1 
WHC-SD-EN-TI-173, Rev. 0

\subsection{REFERENCES}

DOE, 1990. Remedial Investigation/Feasibility Study Work Plan for the 300-FF-5 Operable Unit, Hanford Site, Richland, Washington, (DOE/RL 89-14), U.S. Department of Energy, June 1990.

EPA, 1990. EPA Contract Laboratory Program Statement of Work for Organic Analyses, Multi-Media, Multi-Concentration (OLMO1.0). U.S. Environmental Protection Agency, Washington, D.C.

WHC, 1992a. Data Validation Procedures for Chemical Analyses (WHC-SD-EN-SPP-002, Rev. 1), Westinghouse Hanford Company, April 1992.

WHC, 1992b. Data Validation Procedure for Radiological Analyses. (WHC-SD-EN-SPP001), Westinghouse Hanford Company, 1992.

GW6.FR 


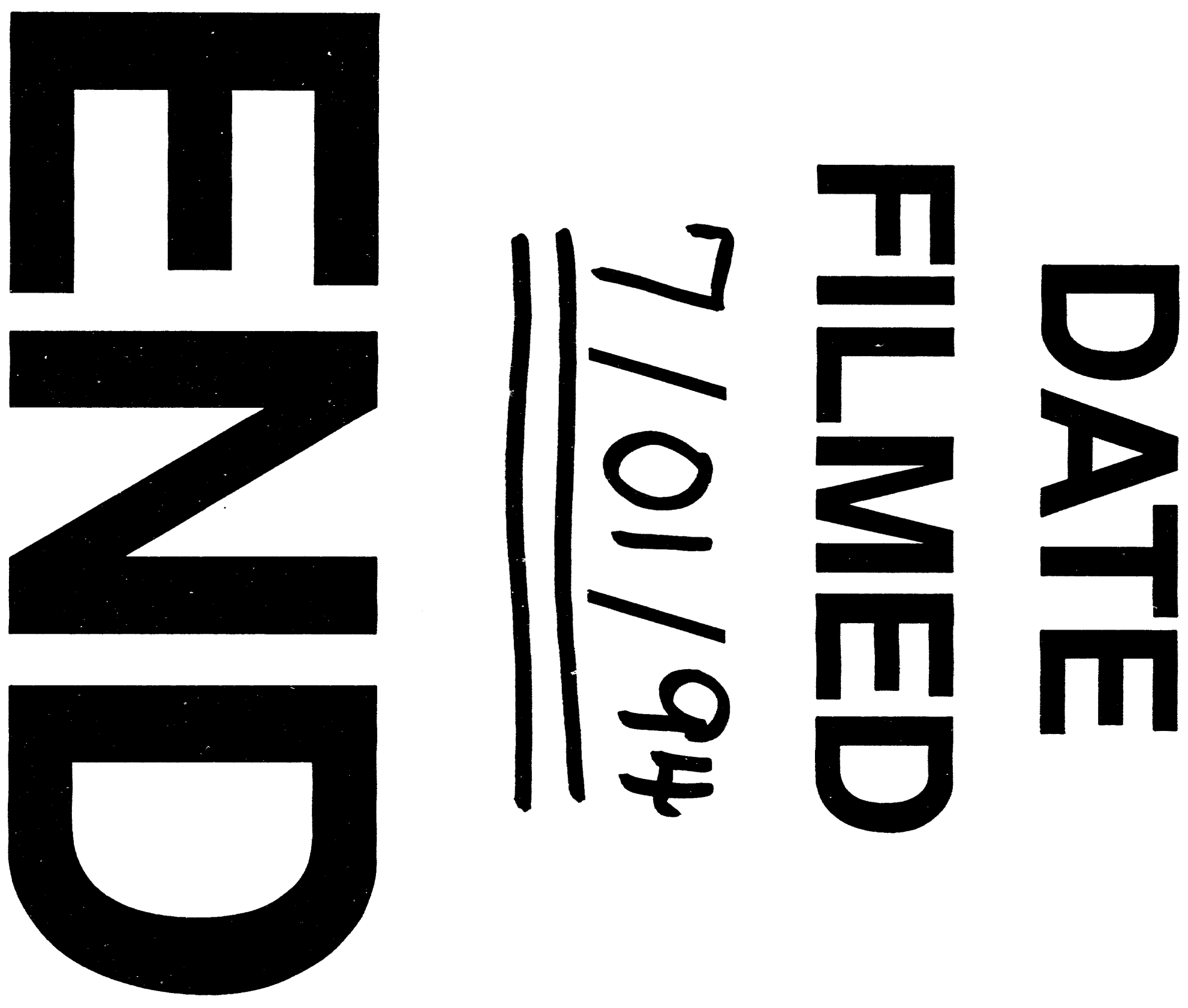


